\title{
Photos of (no)thing: The becoming of data about sexuality at school
}

Louisa Allen

University of Auckland le.allen@auckland.ac.nz

\begin{abstract}
This paper asks, what 'newness' (Springgay \& Zaliwska, 2015) does a new materialist feminist engagement with photos of 'nothing' produce for thinking about images as data in research about sexuality at school? Somewhat unusually, this paper takes as its focus photos of what appear to be, nothing. These indecipherable photos were captured by student photo-diarists as part of research into the sexual cultures of schooling. Traditionally, these photos would not constitute data because they contain no identifiable people or objects, are blurry and were classified by photo-diarists as 'mistakes'. This paper involves a revisiting of these images drawing on the work of Barad (2007), Hultman and Lenz Taguchi (2010) and MacLure (2013). It considers how ideas around onto-epistemology, intra-activity and agential realism might undo and unknow the researcher's previous encounters with them. The paper argues feminist new materialism challenges the nature of what counts as data about sexuality at school and thereby the ontology of data about sexuality itself.
\end{abstract}

Keywords: Sexuality research, Onto-epistemology, newness, wonder, new materialist feminism

\section{Introduction}

This paper is about photos of nothing. Or rather, that is how I perceived these indecipherable images containing no identifiable objects or people. These photos were generated by student photo-diarists as part of research into sexuality at school. The project was concerned with understanding how unofficial meanings about sexuality were produced in two secondary schools in Aotearoa-New Zealand $^{1}$ (see Allen, 2011). Employing a visual methodology (Rose, 2007) students aged 16-17 years were given disposable cameras to take photos of how they learned about sexuality over seven days. Conceived within a feminist post-structural framework (Weedon, 1987), my aim was to understand what these moments revealed about the sexual cultures of schools during a photo-elicitation interview (Pink, 2007). With images splayed before us, photo-diarists selected half a dozen to discuss. Amongst the images of couples holding hands, stealing kisses and portraits of students who were romantically desired, sat the photos of nothing. These images were composed entirely of over exposed splashes of colour (see Figure 1), or dark and grainy with orientation off-kilter as if the camera had gone off whilst falling (see Figure 2). There were no discernible people or things in these images, only traces of them, such as a portion of a chair and someone's back (Figure 3 ) and a section of a student's leg and lower torso (see Figure 2). These images appeared to contain nothing to do with sexuality at school and photo-diarists never spontaneously talked about them. Once during an interview, I directed a student's attention to one such photo and she succinctly explained, 'that one was a mistake'. Subsequently, when organising these photos for analysis - I left these images out. I 
dismissed them as data about sexuality at school, because they were, as the photo-diarists indicated, mistakes....unintelligible, unusable and uninteresting photos of nothing......

Figure 1

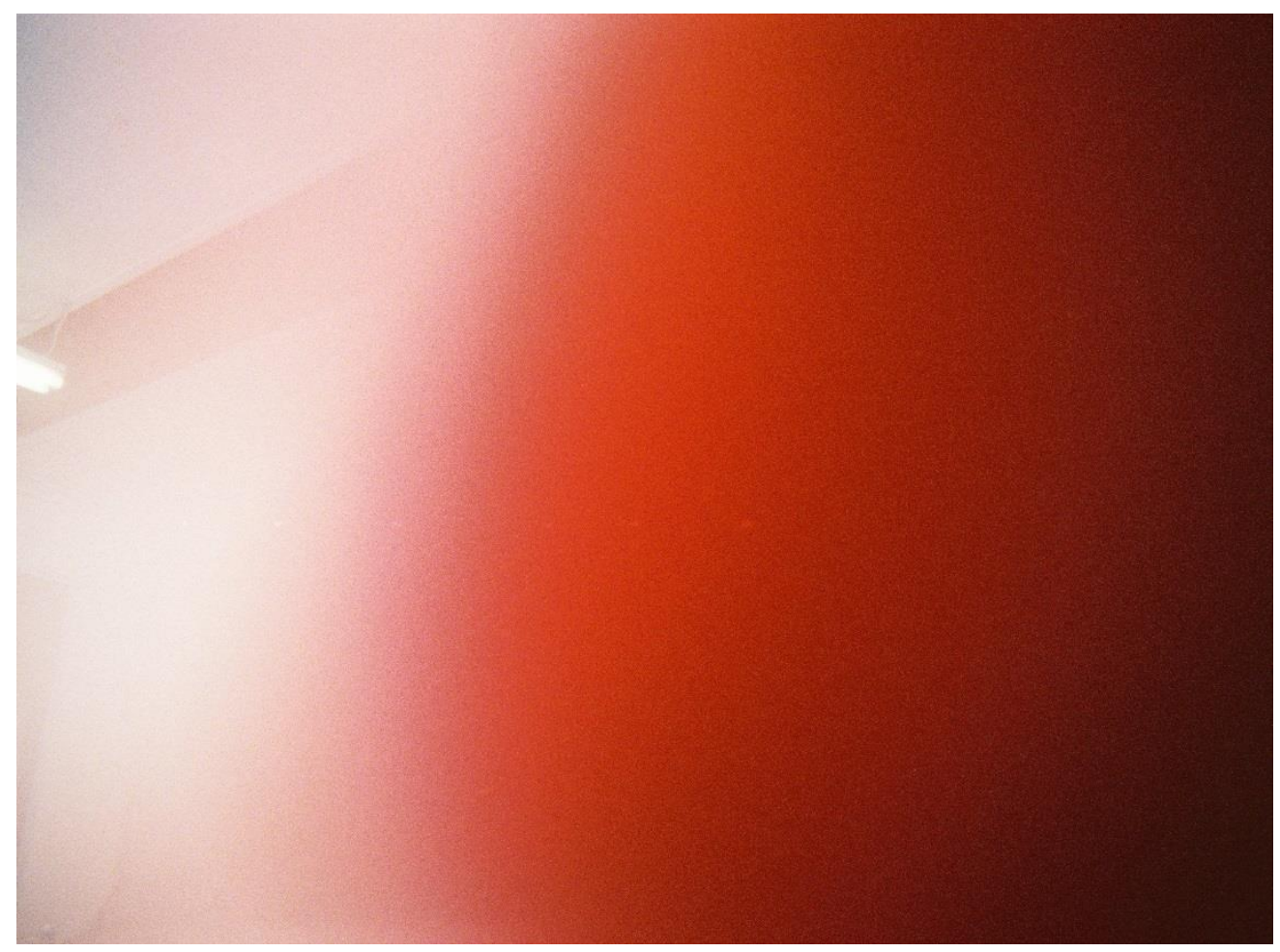

This paper explores what photos of nothing become when considered with-in ${ }^{2}$ a new materialist feminist ontology. It is concerned with what 'newness' (Springgay \& Zaliwska, 2014, p.137) such an engagement might produce for thinking about images as data and knowledge about sexuality generated by school-based research. I attempt to respond to Koro-Ljungberg and MacLure's (2013) provocation to, '......problematize conceptualisations of data as known, familiar, and inert objects, and to imagine more complex, creative and critical engagements with data in the conduct of research' (p.219). To do so, I draw on the work of new materialist feminists ${ }^{3}$ such as Barad (2007), Hultman and Lenz-Taguchi (2010) and MacLure (2013) to unknow and undo my previous encounters with these photos. As Schnabel (2014) highlights, '.....new feminist materialisms challenge dichotomies of human/non-human and life/non-life in a post-humanist........project' (p.11). An implication of this unsettling is the decentring of the human researcher as determining the nature and meaning of research (Nordstrom, 2015) and acknowledgement of matter as agential. This challenge forms part of the work of the paper.

My argument is that feminist new materialism challenges the nature of what counts as data about sexuality at school and the ontology of data about sexuality itself. In this regard, the paper is concerned with visual research methodology and the ontology of data it produces about sexuality at school. Like St Pierre (2013) I am interested in questions around the appearance of data such as who gets to determine that data about sexuality has 'appeared' as well as what it looks like when it does? ${ }^{4}$ Within feminist new materialist thought there is no separation between epistemology and ontology. That is, the way we think about knowledge (including how we derive it methodologically) and the nature of knowledge itself. Rather, there is what Barad (2007) terms onto-epistemology or 'the study of practices of knowing in being' where knowledge is not procured '.... by standing outside the world: we know because we are of the world (p.185). Such a framework co-implicates the 
researcher (along with a plethora of other non-human and non-living phenomena) in the becoming ${ }^{5}$ of data about sexuality at school. Throughout this paper I attempt to reveal my own co-implication in the becoming of what counts as data about sexuality, a process begun in the paper's opening paragraph where I explain my initial dismissal of these photographs. Seeking to decentre the researcher, I pay attention to materiality which within the realms of visual research involves affording a 'more active role' (Jagger, 2015 p.322) to non-living objects such as cameras and photos.

Figure 2

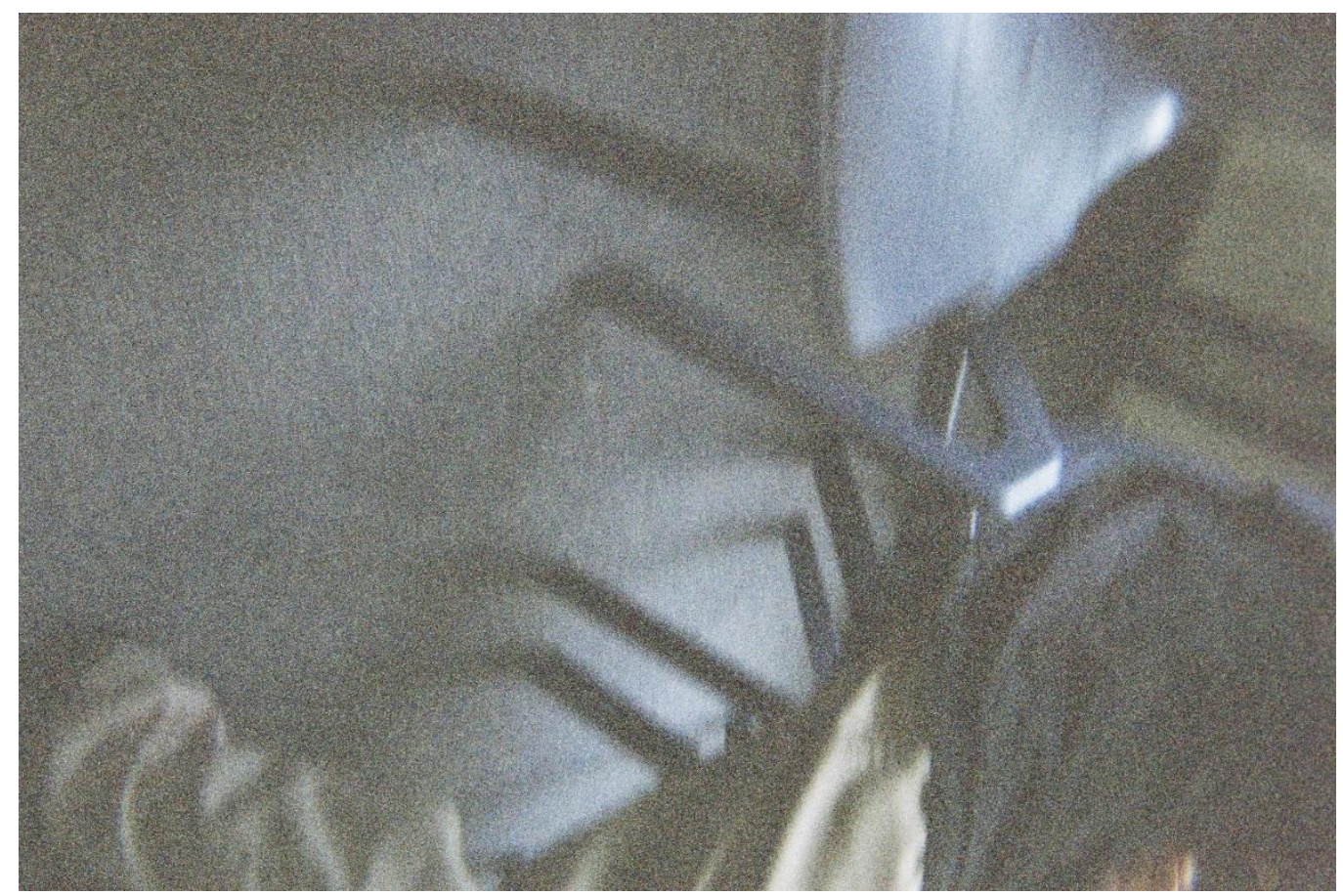

What then might be gained by re-thinking photos of nothing with-in new materialist feminist ontology? In undertaking this work I employ a methodological strategy which Lenz Taguchi (2010) characterises as 'exorbitant deconstruction'. This process involves a 'turning, bending and twisting' of conventional thinking 'to try and displace the meanings of it; in order to identify..... what other analysis might be possible' (Lenz Taguchi, 2010:14). The purpose, is to imagine what 'newness' (Springgay \& Zaliwska, 2014) might be incited by such a process (see also Allen, 2015; Otterstad \& Waterhouse, 2015). 'Newness' as conceptualised by Springgay \& Zaliwska (2015), extends beyond the idea of discovering new findings or meanings about sexuality at school. For them, 'newness' marks a space for '....the more-than intensity of perception. It is the anticipated next, which enables newness to come into existence: the 'more-than' of data' (p.137). 'Newness' in this instance does not seek to result in new empirical insights about sexuality at school garnered by employing a feminist new materialist perspective. Instead, 'newness' marks a space for something that is not nameable in advance and which is ontologically indeterminate (Jagger, 2015: 328). Such indeterminacy will invoke frustration for some readers who must know what feminist new materialism can contribute to understandings of sexuality at school. This indeterminacy is simultaneously the very queer (Barad, 2012) promise which draws others.

The next section establishes how conventionally data, and specifically photographic data is understood to have appeared and who gets to decide when it does? (St Pierre, 2013). To understand how 'newness' might be produced, it is necessary first to establish how these data have been previously thought. The paper then introduces a feminist new materialist critique of a conventional representational account of data highlighting features of this thinking that might reconfigure the 
notion of data in the research scene. A feminist new materialist reading of the photos of nothing is then undertaken, before finally considering what 'newness' might be generated by this process in terms of the becoming of data about sexuality at school.

Figure 3

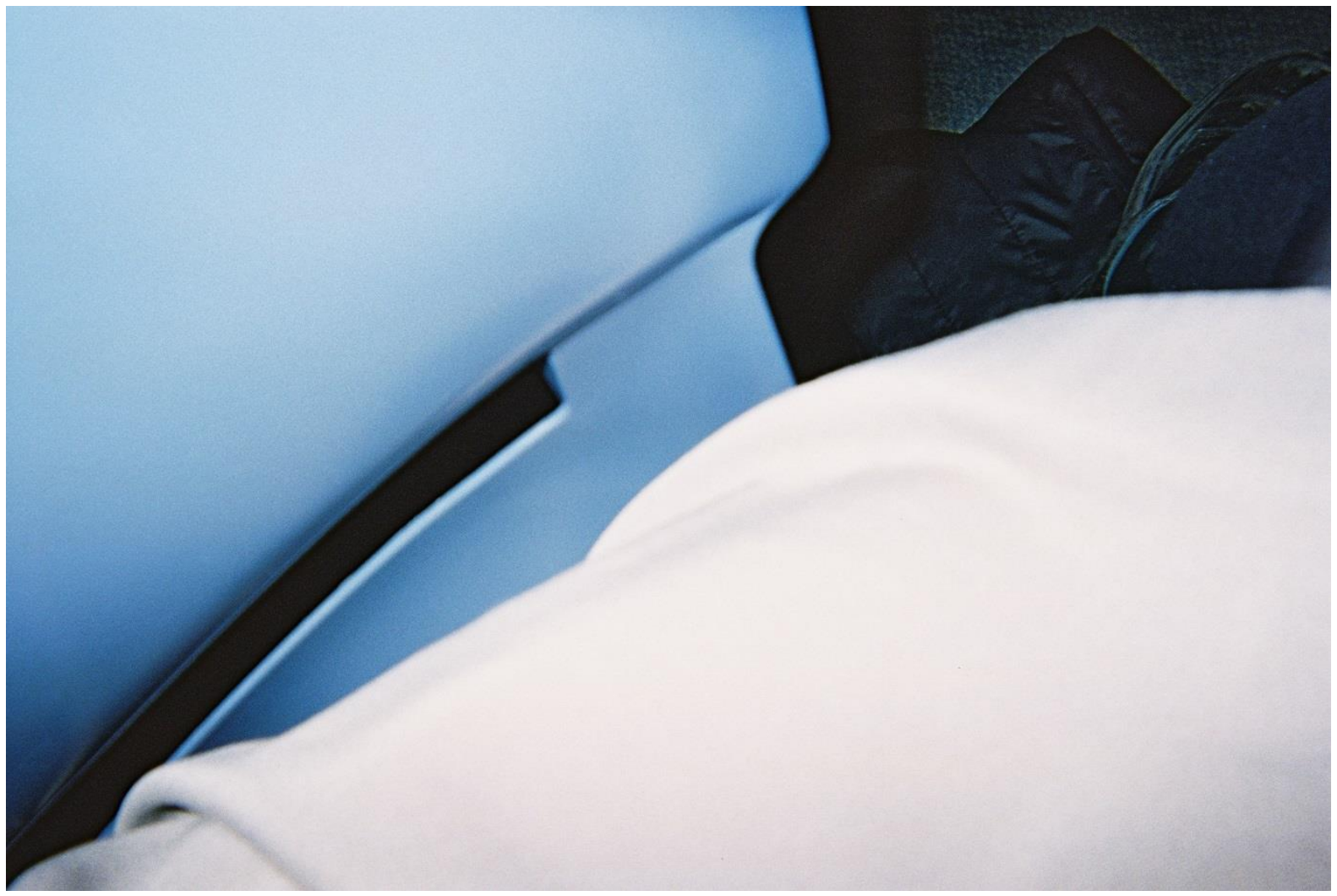

\section{Photos of Nothing: A Representational Reading}

Within what St Pierre calls (2013) 'conventional humanist qualitative inquiry', there is an assumption that data is generally treated as unproblematic (p.223). Koro-Ljungberg and MacLure (2013) ${ }^{6}$ characterise data as '........simply regarded as something we collect and analyse in order to arrive at research conclusions' (p.219). What data does is to describe a given which within a positivist research paradigm is observable as a pre-existing reality. Alternatively, within the logic of postpositivism it is representable through some form of constructionist (or post-structuralist) account. As such, data holds a central place in what Koro-Ljunberg and MacLure (2013) characterise as 'the grand narrative of research' (p.219). Data constitute the building-blocks of research and this status engenders, '.......text books that tell us how to collect it; how to sort and sift it; how to tell the good data - the stuff that is trustworthy, relevant, valid, meaningful - from the bad' ( $p .219)$. The need to decipher 'good' from 'bad' signals that data is not understood as of intrinsically 'good quality'. Information designated as 'bad' is subsequently relegated from the status of 'data' and discarded.

Within the field of visual methodologies the visual content of photos are seen to constitute data. Derived from its historical roots in realism (Pink, 2007) 'good' photographic data is considered to accurately represent the objects and/or people found in the original research scene (Rose, 2007). As Hultman and Lenz Taguchi (2010) explain, 'photographic images have traditionally been understood to mirror the photographed objects, providing an accurate image or representation which is a faithful copy of that which is being mirrored' (p.534-535). A photo's ability to authentically represent 
the world is largely dependent on its quality. Photographic quality is measured predominately by clarity of its features where high definition of objects, people and scenery is significant. 'Good' quality photo data offers a picture that is not blurry or distorted and contains intelligible aspects of a scene that can be analysed. Within the conventions of realist photo methods, the more we can see in an image, the more we can know about an object of investigation. Put another way, the validity and integrity of photo-methods is often contingent upon that which we can see and discern, rather than that which we cannot (for exceptions see Ingold, 2011; Pink, 2013; Larsen, 2006).

In the current project the photos of nothing failed to meet this criteria for 'good' data. Image quality was poor with pictures blurred, grainy and distorted making it difficult to identify anything in them and subsequently discern any meaning. In other photos from this project where people and objects were easily visible, the way such images captured sexuality at school were readily apparent (see Allen 2013). The logic of representation (MacLure, 2013) worked in these photos because they were perceived to successfully convey a reality about sexuality at school. As data, photos of nothing failed to represent anything about sexuality. They were perceived to contain nothing and so could not mean anything in terms of the research objectives.

Returning to St Pierre's (2013) questions above about who gets to determine that data has appeared and what it looks like when it does; data appears in realist visual methodology when photos have clear content from which meaning can be discerned. Who gets to decide when data appears is the human photo-diarist and researcher. What counts as data is decided when interviewees fail to speak about photos of nothing and when the researcher validates their disregard for these images by dismissing them as data to be analysed. Within this paradigm that privileges human agency, photos have no status other than that of 'dumb matter' (Massumi, 2002, p.173). Photographs as data are rendered '.......passive objects, waiting to be coded or granted shape and significance through the interpretive work of researchers' (Koro-Ljungberg and MacLure, 2013 p.219). In representational accounts of visual research, it is the human photo-diarist and researcher who get to decide when data appears about sexuality and what it looks like when it does.

\section{A new materialist feminist critique of representation}

A new materialist feminist critique of representation has 'radical implications' (MacLure, 2013 p.660) for realist visual methodology in the way it encourages us to reimagine the relationship between human researcher and data. Representational accounts of research exhibit what Hultman and Lenz Taguchi (2010) describe as an 'anthropocentric gaze'. This gaze institutes a hierarchical separation between the researcher and the object of investigation according humans 'a privileged and foundational 'point of view' (Colebrook, 2002 p.161-2). Within this dyad, humans are placed above other matter in reality cementing what Hultman and Lenz Taguchi (2010) characterize as 'a kind of human supremacy or humancentrism' (p.526). According to these researchers, the problem with anthropocentrism is that, 'it reduces our world to a social world and neglects all other non-human forces that are at play' (Hultman and Lenz Taguchi, 2010 p.539-540). Since humans are considered the exclusive point of constitution for (human) language and discourse (Alaimo and Hekman, 2008) agency and meaning are restricted to, and regulated by, these realms of articulation. In an anthropocentric version of visual research, humans control the camera deciding what it will capture. Cameras, and photos as their products, are not perceived as having agency or volition of their own, instead they simply represent passive tools for human manipulation.

Another way new materialist feminists challenge representational accounts is by suggesting data can become already coded with latent meaning. Springgay and Zaliwska (2014) drawing from Deleuze explain, 'That is the essence of concrete method. We are forced to being with words, phrases and propositions, but we organize them into a limited corpus that varies depending on the problem raised' (p.138). The effect of such reliance on discourse and language is that it closes down new 
possibilities for engaging with data and producing something more (Blaise, 2013). Pyyry (2015) illustrates this effect in her research around teenage girls 'hanging out' in Finland. She describes how conventional analysis of photo-data, which in her case involved photos of girls in various leisure locations, can get caught in a representational bind.

Even when pictures show us interesting aspects of young people's lives, I argue that using photographs as data creates a danger of stiffening and aestheticizing reality. A picture often gives us only a narrow and essentialist account of the 'reality' of young people's lives. Therefore, even when photography is taken as a research method, it is fundamental to remember that visual perception is only one of the ways in which we sense with the world (Pyyry, 2015 p.150).

New materialist feminists like Pyyry (2015) encourage researchers to find ways of creating 'newness' with research beyond conventional representational accounts that rely on human perception. This process might entail, finding ways of 'activating thought that is experienced rather than known, that is material and affective, and where experience accounts for 'more than human' encounters' (Springgay \& Zaliwska, 2015 p.136).

New materialist feminists also refuse a foundational tenet of representational research accounts; namely the idea that the researcher is a distinct entity who can reflect upon an object of investigation perceived as separate from them. Barad (2007) via her theory of agential realism insists instead on 'the inseparability of observed object' and 'agencies of observation' (p.114). In making this claim Barad draws on the work of Neils Bohr in quantum physics. This approach challenges the notion that humans and things are individually determinate entities, ontologically prior to their representation. Such thinking has implications for representational accounts where the researcher, in order to reflect upon their data, must be seen as ontologically separate from it. Barad posits an alternative conceptualisation of reality where the primary ontological unit is not an independent object with inherent boundaries and properties, but rather 'phenomena' (Barad, 2007: 127). Phenomena are produced in intra-active practices of knowing-in-being, or what is described above as onto-epistemology. Intra-actions differ from more conventional ideas around inter-action in that they involve any actions between human or non-human matter that do not have distinct or inherent boundaries. By contrast, inter-actions occur between two or more distinct people or objects that operate independently and are perceived to have intrinsic qualities. Jagger (2015) summarises the significance of this thinking for representational thought; 'Bohr's work in quantum physics undermined both Newtonian physics and Cartesian epistemology, with its tripartite structure of knowers, words, and things and its distinction between subject and object, which in turn underpins representationalism' (p.327).

When we extend this thinking to a consideration of school-based sexuality research it has radical implications. As Hultman and Lenz Taguchi (2010) explain, this ontology of reality means, 'We can never reflect upon something on our own' as this implies a separation between the viewer and viewed (p.538). Rather, reflection occurs via intra-actions between heterogeneous bodies and agents instead of as an occurrence that is confined within the mind of a distinct and determinate researcher. Subsequently, 'we can never read the data in order to unfold 'what actually happened' as if reading the event 'behind' or 'before' the photographic image' (Hultman and Lenz Taguchi 2010 p.537). Instead, in the current sexuality research, the researcher, the camera and the photographs come into being (that is, become) in the same moment of intra-action. In this model, the researcher cannot say photos of nothing mean this about sexuality because she is not ontologically prior or separated from them.

The concept of onto-epistemology allows Barad (2007) to rethink matter as playing an active role in discursive-material intra-actions and challenge the premises of representationalism. Agency is no longer tethered to notions of the subject (or subjectivity) and the workings of discourse. As Schnabel 
(2014) writes, '........new feminist materialists call us to rethink subjectivity and agency moving us away from singularity to a collective distributive agency, centred not in a single living being but an assemblage of living and non-living vibrant matter (Bennett, 2010 p.11). In this version of agency, humans (and other life forms) are dethroned, enabling non-human matter and things (i.e. the nonliving) to be 'potentiating - and even agentic' in the facilitating of activity via their intra-actions (Schnabel, 2014: 11). As such, 'materiality' is always more than 'mere' matter', an excess...' and instead can be seen as 'a force, vitality.... [that is] self-creative, productive unpredictable' contingent upon a set of intra-actions (Coole and Frost, 2010:9). These ideas enable a reconfiguration of data about sexuality as 'dumb matter' that passively awaits human interpretation to give it life and significance. Within an agential realist conceptualisation of matter, data itself can be seen as a constitutive force working upon the sexuality researcher. This conceptualisation establishes a very different set of ethical relations for sexuality research. Here, the vibrancy of matter must be taken into account and power is not the preserve of (the human) researcher/researched.

New materialist feminists characterise the idea of data as an agential force in various ways. Reflecting on her own visual research project Pyyry (2015) explains that she does not understand her photos as constituting 'data' of the world, instead she '....view[s] photographs as capable of inspiring action, of giving a 'push' to thinking' (p.150). This perception is not of data as something which obediently complies with the researcher's codification but which exhibits a vibrancy that does something to the researcher. MacLure (2013a) names this potentiality a kind of 'wonder', an affect that,

\begin{abstract}
can be felt on occasions where something - perhaps a comment in an interview, a fragment of a field note, an anecdote, an object, or a strange facial expression - seems to reach out from the inert corpus (corpse) of the data, to grasp us. These moments confound the industrious, mechanical search for meanings, patterns, codes or themes; but at the same time, they exert a kind of fascination, and have a capacity to animate further thought. (p.228)
\end{abstract}

The capacity of 'wonder' to inspire further thought derives from the kind of mind-space it carves between ignorance and knowledge. MacLure (2013a) describes this cerebral site as marking the 'end of unknowing and the beginning of knowing' (p.228). Data that provoke 'wonder' cannot be known to the researcher via the usual means of capturing and representing their meaning. Instead, such data is decidedly unknowable in its capacity to slip out of the researcher's codifying grasp. It refuses to be pinned by easily decipherable meaning and thus is unknowable to the researcher in any totalizing or satisfying way. In addition, 'wonder' is not simply a cerebral event but 'pre-eminately material: it insists in bodies as well as minds.......we may feel the wonder of data in the gut, or the quickening heartbeat...' (p.229). 'Wonder' can also leave the researcher feeling a multitude of affects that are not necessarily positive, such as perplexity, disconcertion, frustration and even disgust.

The photos of nothing in the current research might be seen as inspiring 'wonder'. However, unlike other images of sexuality photo-diarists produced, they did not elicit participants' animated talk, humour or delight when explaining and exploring them. Neither did they evoke visible feelings of discomfort or distress as when photo-diarists discussed negative experiences associated with photos of cheating boyfriends/girlfriends or episodes of homophobia. The photos of nothing, uniquely produced no detectable feelings from participants - they were simply dismissed. These photos had exactly the same affect on me (as researcher) who saw nothing in them, felt nothing about them and simply discarded them. Affect as nothing, is an under examined element of the burgeoning field of affect theory where predominately all affects are understood as having positive and/or negative affiliations (Gregg \& Seigworth, 2010). Within the current research however, the form of 'wonder' by which this data grasped me can be understood as an affective nothing. The significance of this affect must be contextualised within the empirical landscape of sexuality research which is often infused 
with controversy (see Allen et al, 2013) and subsequently evokes feelings of anger, pleasure, fear, embarrassment and resentment. To feel nothing within such an emotionally charged empirical space, is somewhat of a revelation.

There is a kind of unintelligibility about an affective nothing being able to animate further thought. How can nothing, produce anything? It is this point of unknowing (or rather the limits of knowing) that for me signals 'wonders' presence. As indicated by MacLure (2013a), 'these moments confound the industrious, mechanical search for meanings' (p.228) because 'wonder' manifests on the precipice of complete indecipherability of these images. They evade codification because they are perceived as containing nothing to attach meaning about sexuality too. In representational accounts, meaning must attach itself to something, but there is seemingly nothing sexual in these photos to decipher. The photos of nothing signal a point of unknowing, which for new materialist feminism marks the beginning of knowing. This is the space which Springgay and Zaliwska (2014) conceptualise as 'newness'.

\section{A new materialist feminist reading of photos of nothing}

So how then might we apply a feminist new materialist reading to these photos that opens space for 'newness'? I want to draw here on the concept of 'pure edging' as taken up by Springgay and Zaliwska (2015) in their arts-based research involving photographs. Drawing on Massumi's (2011) work, Springgay and Zaliwska (2015) describe pure edging as way of engaging with photographs that involves a methodological cut that manifests as 'a [v]irtual line.... [a]n insubstantial boundary, itself imperceptible.....which does not effectively enclose' (p.89). Instead of examining photos for their content, pure edging is about discovering the limits of data as spaces of creativity in which the researcher is co-implicated. In their own words;

........in letting go of our desire to capture these images with pre-formed humanistic categories, we learned to think about the images as more-than. In learning to pay attention to the edges of representation, we simultaneously let go of our desires to instrumentalize and impose meaning on the images, and found the audacity to entangle ourselves with the data-to-come (Springgay and Zaliwska, 2015:139).

Such virtual cuts across data draw attention to its edges highlighting relationality as well as generating 'newness' as a consequence of as Springgay and Zaliwska explain, the 'more-than' they contain. This is a very different analytic process to a conventional representational account where meaning is extracted from photos and then tracked across a set of images. Pure edging is concerned with offering data a life 'outside of' its capacity for codification '...by asking us to pay attention to what is not being said, to disjunctions, paradoxes, and contradictions' (Springgay and Zaliwska, 2015:139). The point is not to fill in the gaps to make better meaning from the photos before us. Rather, the aim is to create a space where something new can emerge. This 'newness' is not representable however, because feminist new materialism renders it indeterminate. This quality of indeterminacy simultaneously bestows such 'newness' with unknown potential.

One way of engaging in pure edging is to choose a seemingly small and insignificant piece of data to concentrate on. Drawing as much as possible from a piece of photo data enacts a cut that Springgay and Zaliwska (2015) argue can reveal a 'pure edge'. Opening up data to its edginess means relinquishing the desire to 'capture' an event either through attention to detail or through a totalizing perspective that encapsulates a story' (Springgay and Zaliwska, 2015: 140). In their own research exploring how school-based social practice artists can create conditions for innovative and sustainable pedagogical change, Springgay and Zaliwska attempt to unsettle the conventional idea that images can speak for themselves. Searching through their image bank they cut into their data by focusing on images where different organic materials touch (e.g. a beach scene revealing where 
sea and rock meet). Such pictures defy easy reconciliation as meaning about school-based social practice artists and pedagogical change, as their concentration on matter as rock and sea, appears to bear no relationship to these issues. This form of pure edging draws attention to photo data which appears minor and therefore in a representational account, irrelevant to the research aims.

In the current research, concentration on photos of nothing can be seen as a form of pure edging. These images already constituted the edges of data because I had designated them as not constituting data at all. Their relevance to insights about sexuality was perceived so miniscule that they appeared to signal the limits of data in and of themselves. Jackson and Mazzei (2012 p.139) describe the need to push data to exhaustion in order to open up something new. Within a conventional representational research account, paying intensive attention to photos of nothing constitutes an exhaustion of data. What is considered exhaustive about this exercise is that it (pointlessly) attempts to extract meaning from nothing.

It is only in exhausting these photos' quality of nothing as part of the process of pure edging that room for something 'new' might emerge. Photos of nothing constitute the limits of data because no data/meaning about sexuality could be found in them. Their content was unintelligible as representational of meaning about the sexual cultures of schooling. Yet, these photos are undeniably products of a research investigation into the sexual cultures of schooling. More specifically, they are material products of the research process (as paper and ink) and as such irreducible as 'things'. What is also irreducible about them is the fact they contain 'things' both nonhuman and human such as a fragment of chair, segments of student bodies and splashes of colour. Via the exhaustion of their quality of nothing, a new materialist ontology engenders the possibility that these images are, as the title of this paper suggests, also photos of (no)thing. Here, the 'thing' in '(no)thing', references these photos as irreducible to material things as paper and ink and that they contain 'things' such as parts of a chair. The '(no)' in (no)thing refers to the fact these photos mean nothing within a representational account of sexuality at school.

Within an agential realist framing that recognises these photos as matter, pure edging helps us to understand how they perform their materiality. Pure edging encourages us to, '..........think about the potential for an image to call attention to its mode of perception. The photos of (no)thing can be seen to call attention to their mode of perception by refusing representation. They cannot be coded in the manner of other photos because I (as researcher) cannot make intelligible what I see in them and reconcile this with the research aims. When I ask myself what I am looking at, the answer is nothing - a conclusion supported by the photo diarist who told me this photo was a mistake. What pure edging enables is an understanding that, 'It's not the form [of the photo] that matters, but its capacity to alter you, to undo you, to move you toward the edging, and thus shift figure and ground' (Springgay and Zaliwska, 2015 p.140). Via its refusal to be coded and made intelligible by me, this photo pushes me to pay attention to its mode of perception. This mode of perception is my anthropocentric rendering of its (un)importance as data about sexuality.

\section{A new materialist feminist reading of the camera}

This ontological reconfiguring of photos of (no)thing from passive data, to that which has the capacity to 'give a push to thinking' (Pyyry, 2015: p.150) can be extended to other elements of the visual research process. For example, within conventional understandings of visual research practice cameras are often perceived as inanimate tools. Like the photo data which eventuates from them, they are considered 'dumb matter' exhibiting no agency of their own. Any agency attributed to cameras is seen as engendered by humans who activate them. Cameras have no capacity to animate on their own because they are composed of 'dead matter' and therefore incapable of independent movement like living breathing organisms. Subsequently, all eventuating photos are perceived to be caused by human action and not of a camera's own doing. Even photos not meant to be taken are 
attributed to human agency, because the mistake is seen to be a human one. This was the representational logic I originally applied to the photos of (no)thing - that they occurred because of human error.

Recently, while mining the interview transcripts again for another paper (see Allen, 2015) I came across an exchange in the data corpus that grasped me. It occurred at the edge of an interview with a participant when formal discussion had finished and we were sorting through and numbering photographs. Consumed by this task, I had forgotten to turn off the digital recorder so it caught our exchange which went like this.....

Louisa: $\quad$ Are there any photos that we haven't looked at or numbered?

Camile No, except that one [pointing to Figure 3] since that was of a chair.

Louisa: What happened there?

Camile: $\quad$ As we [Camile and her friend] were playing with the camera it went off, and it went off, we were trying to work out where the flash was.

As an example of pure edging this exchange marks the limits of data as technically the interview had finished. It is a miniscule moment, never originally counted as data because it occurred outside the parameters of the interview and appeared to represent nothing about the sexual cultures of schooling. Despite this exchange meaning nothing about sexuality, it had been transcribed as part of the data set which I have read innumerable times previously. Now read in intra-action with new materialist feminist thought it reaches out to me giving a push to my thoughts. The lines '.....the camera it went off, and it went off....' previously interpreted as an insignificant repetition seem to, as MacLure (2013) describes it, 'glow'. 'It went off, and it went off' are words that give presence to the camera as launching into its own capturing of data about sexuality at school. The camera's volition manifests in the moment the photo-diarist says 'it goes off' despite her not wanting it to, and via the fact this moment is now significant even though she and I, never intended it to be counted as data.

It is important to be clear that I do not offer the narrative above as evidence of the camera having an intrinsic agency of its own. To do so slides back into representational logic whereby an ontological separation exists enabling the researcher to interpret the words of the participant as meaning that cameras can collect data on their own. Within a new materialist feminist onto-epistemology this is an impossibility because the participants and camera are not ontologically distinct. As indicated above, the researcher, the data and the photographs come into being (become or are ontologically realised) in the same moment of intra-action. It is via this becoming that agency occurs, not as the preserve of either the camera or participant, but as a consequence of the unique intra-actions of these phenomena. This uniqueness is not because they are distinct entities inter-mingling, but because they are particular ontologically indistinct phenomena. Phenomena comprising of cameras, narrative transcription, the researcher, new materialist feminist theory and other human-nonhuman matter, known and unknown to me which this act of pure edging has not evoked. This is a different conceptualisation of agency from traditional causational accounts. Causational perspectives see power working in a unidirectional manner between human and non-human objects. In this traditional rendition, any activating force is always seen to emanate from the human (Coleman, 2014). Coleman (2014) explains that the material turn 'relinquish[es] the unidirectional model of causation in which either culture or biology is determinative and instead........adopt[s] a model in which causation is conceived as complex, recursive, and multi-linear' (p.71). Within this conceptualisation agency is not the preserve of the photo-diarist, the researcher or even the camera but occurs withineach-and-between them as intra-acting phenomena. 
As Haraway (1991) points out, 'acknowledging the agency of the world in knowledge makes room for unsettling possibilities' (p.199) particularly for what we currently conceptualise as 'ethical research' or as it is known in its institutionalised form, 'Research Ethics'. What might it mean for research by humans to relinquish (human-presumed) control of, when sexuality data appears, and what it looks like when it does? A new materialist feminist engagement with 'photos of nothing' creates this site of 'newness' (Springgay \& Zaliwska, 2015) from which such a question about sexuality research can unfold.

\section{Unending Matters}

In concentrating on photos of (no)thing this paper is not a call for sexuality researchers to pay attention to indecipherable images in their visual projects from now on. Neither is it a call to understand sexuality researchers and other humans as now obsolete in the research process. This paper does not invite a reversal of causational conceptualisations of power and now charge matter, such as cameras and data, with their own agency that usurps humans. Instead, this paper has offered consideration of these things as sites to access 'newness' in thinking about what counts as data about sexuality at school and the very ontology of that data.

So what 'newness' eventuates from this feminist new materialist analysis in thinking about data collected as part of sexuality research? Some readers will want an explanation of what new knowledge about sexuality at school has been produced as a result of applying a feminist new materialist analysis. However, this expectation is framed within a representational account which posits the researcher as ontologically separate from new materialist feminist thought, data about sexuality and the process of its collection. When we understand these elements as intra-actively entangled, the intelligibility of such a question is dismantled. This dismantling effect is part of the 'newness' (i.e. a space beyond the meaning of data), which new materialist feminist thought opens up.

While these photos cannot be read as representing knowledge about sexuality at school they form part of the becoming-of-data about sexuality in this context. That is, they cannot be discounted as 'bad' data because they contain no meanings about sexuality. These photos of (no)thing are therefore as important in terms of what counts as data as other pictures directly referencing a conventional understanding of sexuality (e.g. girlfriends/boyfriends hugging). Within a new materialist feminist account these photos of (no)thing form part of an entanglement of things, nonhuman, human, living matter, dead matter, affects and phenomena unknown/inaccessible to this human researcher that make up what data about sexuality at school looks like (St Pierre, 2013). Thinking about the becoming of data in this way, not only challenges what counts as important data, but also reconfigures the ontology of sexuality data itself.

New materialist feminist thinking enables researchers to see data about sexuality as an endless intra-active un/en/folding which encompasses the material human-non-human world and extends beyond the notion of 'sexual identity'. This does not engender the conclusion that new materialist feminism is just another framework for representing matter in which the ontology of sexuality is an unending (relativist) flow of (every)thing. This paper and the thoughts it contains constitute an agential cut which is not characterised by a relativist approach or oblivious to the importance of ethical research, but configures ethical responsibility differently. As Barad (2007) writes, such responsibility involves, 'an accounting of the constitutive practices in the fullness of their materialities, including the enactment of boundaries and exclusions, the production of phenomena in the sedimenting historiality, and the ongoing reconfiguration of the space of possibilities for future enactments' (p.390-391). 
I undertake this work in this paper by drawing attention to my initial dismissal of these photos as an anthropocentric enactment of 'exclusion' and 'boundary' making in what counts as data about sexuality at school. I acknowledge the 'fullness' of these photos' 'materiality' by rendering them irreducible to matter and therefore not 'nothing'. These photos are 'things' that give a push to my thinking and are intra-actively involved in the becoming of data about sexuality at school. The 'sedimenting historiality' of these photos of (no)thing has been traced via a conventional representational reading of their meaning which I attempt to undercut with new materialist feminist thought. What I do next, can be seen in the spirit of an 'ongoing reconfiguration of the space of possibilities for future enactments' (Barad, 2007:370) in the field of sexualities studies.

This reformulation of the ontology of data about sexuality at school opens 'newness' for thinking about the ontology of sexuality more generally. Within an agential realist framing of the world as intra-actively entangled, the logical progression of the argument that the ontology of data about sexuality at school can be reconfigured, is that, so too can the ontology of sexuality itself. Typically, understandings of the ontology of sexuality render the human body and human individual as the privileged site where sexuality happens (Lambevski, 2005; Allen, 2015). However, within a new materialist feminist approach the ontology of sexuality becomes within whatever constitutes the immediate research-creation (Springgay \& Zaliwska, 2015). In the context of the current research, this occurs via the intra-activity of photos of (no)thing, camera, new materialist feminist ideas, human researcher and human photo-diarist. If we understand what counts as data about sexuality differently, then what does this mean for the way we understand the ontology of our object of investigation: sexuality itself? This paper is unending in this space of 'newness'......

\section{Endnotes}

${ }^{1}$ Aotearoa-New Zealand is another name for New Zealand which acknowledges the status of Maori as the indigenous people of this country.

${ }^{2}$ This phrasing references the notion of onto-epistemology discussed below.

${ }^{3}$ Throughout this paper I use the phrasing 'new materialist feminist', 'feminist new materialist' and 'new feminist materialist' interchangeably. In the context of this paper it is the proximity of these words to each other rather than their ordering which I wish to focus on.

${ }^{4}$ For others who have explored this question of what counts as data in relation to photographs (but not within the field of sexuality and education) see Osgood \& Giugni (2015).

${ }^{5}$ The process of becoming is explained below.

${ }^{6}$ These authors are drawing on Blaikkie's work here (2003 p.15).

\section{References}

Allen, L. (2015). 'The power of things! A 'new' ontology of sexuality at school. Sexualities. http://dx.doi.org/10.1177/1363460714550920

Allen, L. (2013) 'Behind the Bike Sheds: Sexual Geographies of Schooling'. British Journal of Sociology of Education. 34(1): 56-75. http://dx.doi.org/10.1080/01425692.2012.704719

Allen, L., Rasmussen, M., Quinlivan, K., Aspin, C., Sanjakdar, F., \& Bromdal, N. (2013). Who's afraid of sex at school? The politics of researching culture, religion and sexuality at school. International Journal of Research and Method in Education, 37(4), 31-43. http://dx.doi.org/10.1080/1743727X.2012.754006 
Allen, L. (2011). 'Picture this': Using photo-methods in research on sexualities and schooling', Qualitative Research 11(5):487-504. http://dx.doi.org/10.1177/1468794111413224

Allen, L. (in press). Losing Face?: Photo Anonymisation and the Integrity of Visual Research. Visual Studies. http://dx.doi.org/10.1080/1472586x.2015.1016741

Alaimo, S. \& Hekman, S. (2008). Introduction: Emerging Models of Materiality in Feminist Theory. In S. Alaimo \& S. Hekman (Eds.). Material Feminisms (pp. 1-19). Bloomington and Indianapolis: Indiana University Press.

Barad, K. (2012). Nature's Queer Performativity (the authorised version). Women, Gender and Research, 1(2), 25-53.

Barad, K. (2007). Meeting the universe halfway: Quantum physics and the entanglement of matter and meaning. Durhman: Duke University Press. http://dx.doi.org/10.1215/9780822388128

Bennett, J. (2010). Vibrant Matter: a political ecology of things. Durham: Duke University Press.

Blaikie, N. (2003). Analyzing quantitative data: From description to explanation. London: Sage. http://dx.doi.org/10.4135/9781849208604

Blaise, M. (2013). Activating Micropolitical Practices in the Early Years: (Re)assembling Bodies and Participant Observations. In R. Coleman \& J. Ringrose (Eds.), Deleuze and Research Methodologies (pp. 184-200). Edinburgh: Edinburgh University Press.

Colebrook, C. (2002). Understanding Deleuze. Sydney: Allen and Unwin.

Coleman, R. (2014). Inventive Feminist Theory: Representation, Materiality and Intensive Time. Women: A Cultural Review, 25(1), 27-45. http://dx.doi.org/10.1080/09574042.2014.901098

Coole, D., \& Frost, S. (Eds.). (2010). New Materialisms: Ontology, Agency, and Politics. London: Duke University Press. http://dx.doi.org/10.1215/9780822392996

Gregg, M., \& Seigworth, G. (Eds.). (2010). The Affect Theory Reader. Durham: Duke University Press.

Haraway, D. (1991). Simians, cyborgs and women: The reinvention of nature. New York: Routledge.

Hultman, K., \& Lenz Taguchi, H. (2010). Challenging anthropocentric analysis of visual data: a relational materialist methodological approach to educational research. International Journal of Qualitative Studies in Education, 23(5), 525-542. http://dx.doi.org/10.1080/09518398.2010.500628

Ingold, T. (2011). Worlds of sense and sensing the world: as response to Sarah Pink and David Howes. Social Anthropology, 19(3), 313-317. http://dx.doi.org/10.1111/j.14698676.2011.00163.x

Jackson, A., \& Mazzei, L. (2012). Thinking with Theory in Qualitative Research: Viewing data across multiple perspectives. Abingdon, Oxon: Routledge.

Jagger, G. (2015). The New Materialism and Sexual Difference. Journal of Women in Culture and Society, 40(2), 321-342. http://dx.doi.org/10.1086/678190

Koro-Ljungberg, M., \& Maclure, M. (2013). Provocations, Re-Un-Visions, Death, and Other Possibilities of 'Data'. Cultural Studies <-> Critical Methodologies, 13(4), 219-222. http://dx.doi.org/10.1177/1532708613487861 
Lambevski, S. (2005). Bodies, Schizo Vibes and Hallucinatory Desires. Sexualities 8(5), 570-586. http://dx.doi.org/10.1177/1363460705058394

Larsen, J. (2006). Geographies of Tourism Photography: Choreographies and Performances. In J. Falkheimer \& A. Jansson (Eds.), Geographies of Communication: The Spatial Turn in Media Studies (pp. 243-261). Goteborg: Nordicom.

Lenz Taguchi, H. (2010). Doing collaborative deconstruction as an 'exorbitant' strategy in qualitative research. Reconceptualizing Educational Research Methodology, 1(1), 41-53. http://dx.doi.org/10.7577/rerm.170

MacLure, M. (2013). Researching without representation? Language and materiality in postqualitative methodology. International Journal of Qualitative Studies in Education, 26(6), 658-667. http://dx.doi.org/10.1080/09518398.2013.788755

Maclure, M. (2013a). The Wonder of Data. Cultural Studies <-> Critical Methodologies, 13(4), 228232.

Massumi, B. (2011). Semblance and event: Activist philosophy and the occurent arts. Cambridge, MA: MIT Press.

Massumi, B. (2002). Parables for the virtual: Movement, affect, sensation. Durham: Duke University Press. http://dx.doi.org/10.1215/9780822383574

Nordstrom, S. (2015). A Data Assemblage. International Review of Qualitative Research, 8(2), 166193. http://dx.doi.org/10.1525/irqr.2015.8.2.166

Osgood, J., \& Giugni, M. (2015). Putting posthumanist theory to work to reconfigure gender in early childhood: When theory becomes method becomes art. Global Studies of Childhood, 5(3), 346-360. http://dx.doi.org/10.1177/2043610615597160

Otterstad, A. M., \& Waterhouse, A-H. L. (2016). Beyond Regimes of signs: making art/istic portrayals of haptic moments/movements with child/ren/hood. Discourse: Studies in the Cultural Politics of Education, 37(5), 739-753. http://dx.doi.org/10.1080/01596306.2015.1075727

Pink, S. (2013). Engaging the senses in ethnographic practice: Implications and advances. The Senses and Society, 8(3), 261-267. http://dx.doi.org/10.2752/174589313X13712175020433

Pink, S. (2007). Doing Visual Ethnography: Images, Media and Representation in Research (2nd ed. Vol. London): Sage.

Pyyry, N. (2015). 'Sensing with' photography and 'thinking with' photographs in research into teenage girls' hanging out. Children's Geographies, 13(2), 149-163.

http://dx.doi.org/10.1080/14733285.2013.828453

Rose, G. (2007). Visual Methodologies: An Introduction to the Interpretation of Visual Materials (2nd ed.). London: Sage.

Schnabel, L. (2014). The question of subjectivity in three emerging feminist science studies frameworks: Feminist postcolonial science studies, new feminist materialisms, and queer ecologies. Women's Studies International Forum, 10-16.

http://dx.doi.org/10.1016/j.wsif.2014.02.011 
Springgay, S., \& Zaliwska, Z. (2015). Diagrams and Cuts: A Materialist Approach to Research-Creation. Cultural Studies <-> Critical Methodologies, 15(2), 136-144.

http://dx.doi.org/10.1177/1532708614562881

St. Pierre, E. (2013). The Appearance of Data. Cultural Studies <-> Critical Methodologies, 13(4), 223227. http://dx.doi.org/10.1177/1532708613487862

Weedon, C. (1987). Feminist Practice and Poststructuralist Theory. Oxford: Blackwell. 